\title{
Refractory Mixed Cellularity Classic Hodgkin Lymphoma
}

National Cancer Institute

\section{Source}

National Cancer Institute. Refractory Mixed Cellularity Classic Hodgkin Lymphoma. NCI

Thesaurus. Code C8833.

Mixed cellularity classic Hodg kin lymphoma that is resistant to treatment. 